\title{
Epidemiology of Reemerging Scarlet Fever, Hong Kong, 2005-2015
}

\section{Chun Fan Lee, Benjamin J. Cowling, Eric H. Y. Lau}

Annual incidence of scarlet fever in Hong Kong remained elevated after an upsurge in 2011. Incidence increased from $3.3 / 10,000$ children $\leq 5$ years of age during 2005-2010 to $18.1 / 10,000$ during $2012-2015$. Incidence was higher among boys and was $32 \%-42 \%$ lower in the week following school holidays.

Carlet fever, caused by group A Streptococcus (Strep$\checkmark$ tococcus pyogenes), was a common infectious disease in children before the early 20th century (1) and a major cause of death, with a case-fatality risk $>30 \%(2,3)$. Various factors, including improvements in hygiene and the introduction of effective antibiotics, led to the disappearance of scarlet fever as a major cause of pediatric deaths by the mid-20th century (4). However, reemerging cases of scarlet fever were reported in China in 2011 and the United Kingdom in $2014(5,6)$. Hong Kong also experienced an upsurge in scarlet fever cases in 2011, with a $>10$-fold increase over the previous incidence rate $(7,8)$. The reason for the surge is unclear. One report has suggested that toxin acquisition and multidrug resistance might have contributed (9). Since 2011, the reported number of scarlet fever cases in these locations has remained at elevated levels $(10,11)$. We analyzed the patterns in scarlet fever incidence in Hong Kong during 2005-2015, including the upsurge since 2011.

\section{The Study}

Scarlet fever is a notifiable disease in Hong Kong. We collected individual data, including age, sex, dates of illness onset, and travel history, from 7,266 local case-patients $\leq 14$ years of age (with 3,304 having laboratory-confirmed cases) reported to the Department of Health during 2005 2015. The 2011 upsurge was characterized by a sharp peak (Figure 1, panel A). During that year, 1,438 cases (incidence $17.5 / 10,000$ children $\leq 14$ years of age) were reported, exceeding the total number of 1,117 cases (average incidence 2.1/10,000 children $\leq 14$ years of age) in the previous 6 years $(2005-2010)$. Since then, the annual number of reported cases has remained at a relatively high level, with an average of 14.5 cases $/ 10,000$ children $\leq 14$ years

Author affiliation: World Health Organization Collaborating Centre for Infectious Disease Epidemiology and Control, University of Hong Kong, Hong Kong, China

DOI: https://doi.org/10.3201/eid2310.161456 of age during 2012-2015. The elevated pattern was more apparent in children $\leq 5$ years of age; among this age group, annual incidence averaged 3.3/10,000 children during 2005-2010, jumped to $23.9 / 10,000$ in 2011, and dropped slightly to $18.1 / 10,000$ during 2012-2015.

We investigated the effect of various epidemiologic and meteorologic variables on scarlet fever incidence by using hierarchical multivariable negative binomial regression, accounting for autocorrelation and annual and biannual seasonal trends by using Fourier terms (i.e., including sine and cosine terms in the model) (12). Specifically, we modeled the age- and sex-specific weekly number of scarlet fever cases by age and sex of the patient; linear time trend; average temperature, relative humidity, and rainfall in the previous week (Figure 1, panel B); and school holidays in the previous week. We divided age into 4 groups reflecting the type of school attended: 0-2 years (nursery), 3-5 years (kindergarten), 6-11 years (primary school), and 12-14 years (junior high school). In Hong Kong, school holidays include Christmas ( $\approx 2$ weeks), Chinese New Year $(\approx 10$ days), Easter ( $\approx 10$ days), and summer vacation $(\approx 7$ weeks) (Figure 1, panel A). We included the logarithm of the population size for each age-sex group as an offset term. We first fitted a model with age, sex, and a linear time trend variable for the whole study period, allowing for change in slope after the upsurge, and found a significant change in the linear time trend after the 2011 upsurge $(\mathrm{p}<0.001)$. Therefore, we divided the time-series into preupsurge (2005-2010 [311 weeks]) and postupsurge (2012-2015 [209 weeks]) periods, excluding data in 2011 as a window period of transition.

We then added seasonality to the model in each period (model I; online Technical Appendix Table, https://wwwnc.cdc.gov/EID/article/23/10/16-1456-Techapp1.pdf). Seasonal trends were similar in both periods, with a more pronounced bimodal pattern after the upsurge (Figure 2). The trough ended in early September, when school begins, then disease activity increased to its peak in January, followed by a milder peak in June. Previous studies have indicated a similar bimodal seasonal pattern $(6,13)$.

The final model also included the variables of school holidays and meteorologic factors in the preceding week (Table). This model fitted the scarlet fever incidence satisfactorily, especially for the age groups of 3-5 years and 6-11 years (online Technical Appendix Figure). We observed no significant linear trend in scarlet fever incidence before the upsurge but a mild decreasing trend after the upsurge 


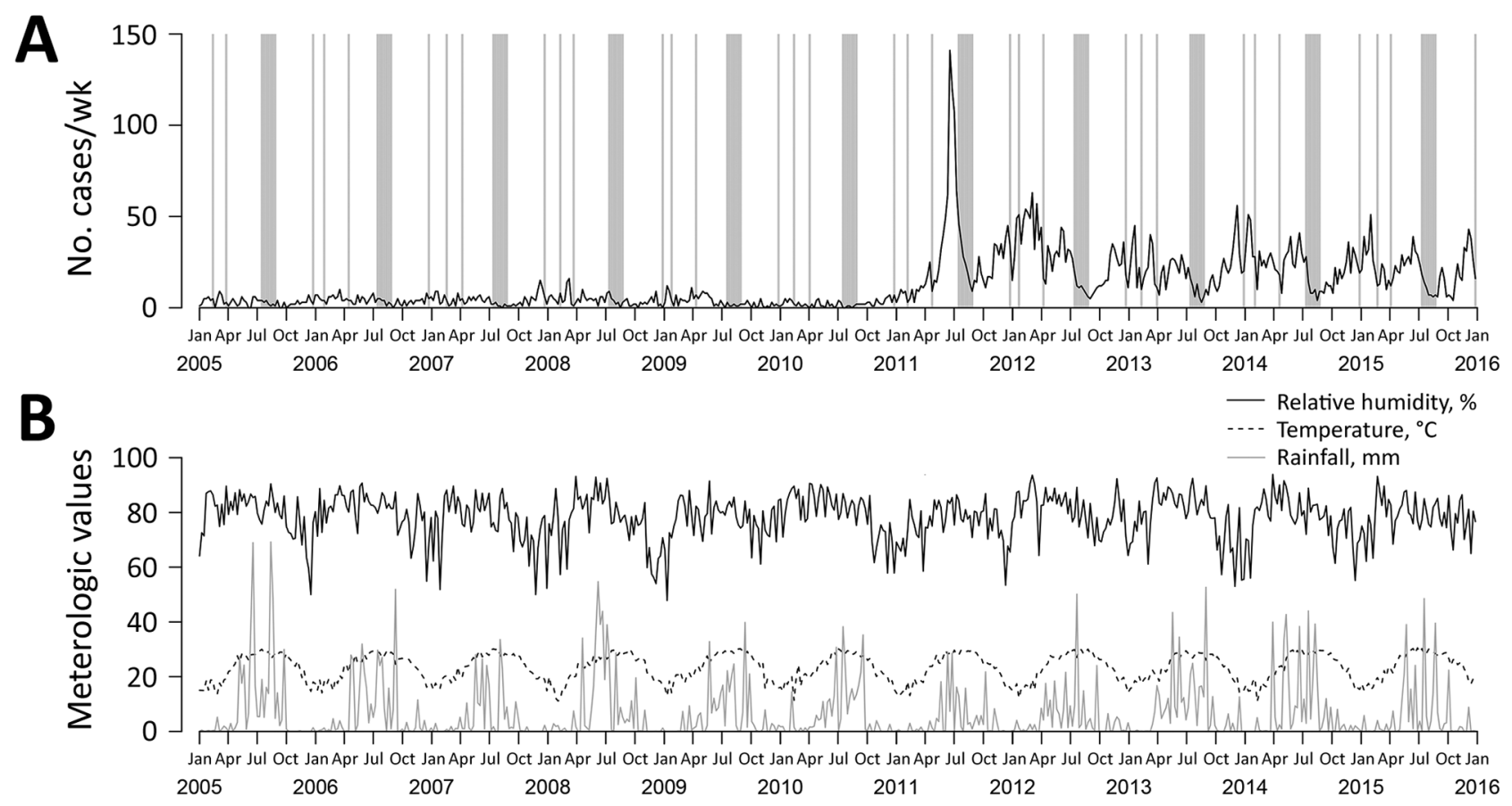

Figure 1. Trends of scarlet fever cases and meteorologic variables affecting reemergence of scarlet fever, Hong Kong, 2005-2015. A) Weekly number of notified scarlet fever cases. Gray bars indicate periods of school holidays. B) Weekly average of temperature, relative humidity, and rainfall.

(adjusted incidence rate ratio [IRR] 0.92; 95\% CI 0.89-0.94) of an $8 \%$ decrease per year. In general, boys had a higher IRR than girls at all age groups, and children $3-5$ years of age had the highest IRR, followed by those $6-11$ years of age and then those $0-2$ years of age, for both sexes. We found a significant age-sex interaction in the postupsurge

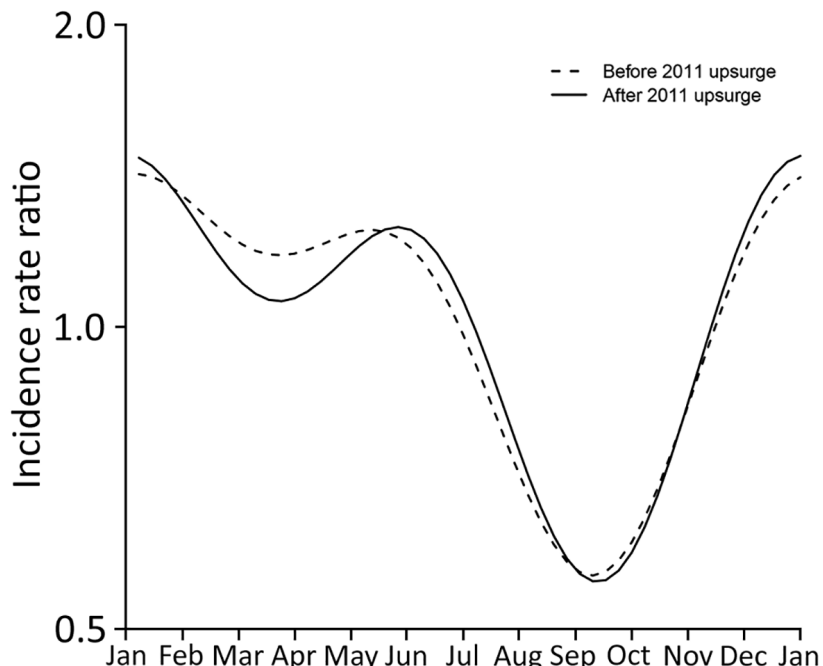

Figure 2. Estimated incidence rate ratios of the seasonal component from the negative binomial regression models before and after the 2011 upsurge of scarlet fever, Hong Kong. Both curves show a bimodal pattern with peak incidence during DecemberJanuary and May-June and lowest incidence in September. period. Specifically, boys had a higher risk for scarlet fever than girls, with an adjusted IRR of 1.08 (95\% CI $0.87-1.34)$ at $0-2$ years of age, $1.47(95 \% \mathrm{CI} 1.32-1.65)$ at $3-5$ years of age, $1.31(95 \%$ CI $1.18-1.46)$ at $6-11$ years of age, and 2.01 (95\% CI 1.26-3.20) at 12-14 years of age. Similar to what has been reported elsewhere $(5,13)$, almost all reported cases in Hong Kong were among children. The relatively high incidence among children of kindergarten age corresponds to the start of schooling, consistent with studies in China (14). The new cohort of children in kindergarten might partly drive the major winter peak. Boys being more at risk than girls might be attributable to more physical interactions or poorer personal hygiene among boys (15).

In 2011, the outbreak reached its peak with 141 cases in the second half of June but sharply fell to 9 cases in the last week of August, at the end of the summer vacation (Figure 1, panel A). However, a clear upturn could be observed once the new school year started. We observed a similar pattern in each subsequent year. Also, school holidays were significantly associated with lower incidence, with IRRs of 0.68 (95\% CI $0.55-0.85)$ before the upsurge (a $32 \%$ reduction) and 0.58 (95\% CI 0.51-0.65) after the upsurge (a $42 \%$ reduction). Together with the observation that the prenursery-age children had a lower incidence, school is probably a major transmission site of scarlet fever because children began to increase their social contact substantially. 
Table. Estimated incidence rate ratios of various epidemiologic and meteorological factors affecting reemergence of scarlet fever, Hong Kong, 2005-2015*

\begin{tabular}{|c|c|c|}
\hline \multirow[b]{2}{*}{ Variable } & \multicolumn{2}{|c|}{$\operatorname{IRR}(95 \% \mathrm{CI})$} \\
\hline & Preupsurge period, 2005-2010, 311 wks & Postupsurge period, 2012-2015, 209 wks \\
\hline Linear time trend, per year & $0.98(0.95-1.02)$ & $0.92(0.89-0.94)$ \\
\hline \multicolumn{3}{|l|}{ Sex } \\
\hline $\mathrm{F}$ & 1.00 & 1.00 \\
\hline M & $1.33(0.92-1.94)$ & $1.08(0.87-1.34)$ \\
\hline \multicolumn{3}{|l|}{ Age group, $y$} \\
\hline $0-2$ & 1.00 & 1.00 \\
\hline $3-5$ & $2.78(2.02-3.90)$ & $3.17(2.63-3.84)$ \\
\hline $6-11$ & $1.29(0.95-1.80)$ & $2.06(1.71-2.50)$ \\
\hline $12-14$ & $0.13(0.07-0.24)$ & $0.14(0.09-0.21)$ \\
\hline \multicolumn{3}{|l|}{ Sex $\times$ age interaction } \\
\hline Boys, 0-2 y & 1.00 & 1.00 \\
\hline Boys, 3-5 y & $1.11(0.72-1.68)$ & $1.36(1.07-1.74)$ \\
\hline Boys, 6-11 y & $1.07(0.70-1.61)$ & $1.22(0.96-1.55)$ \\
\hline Boys, $12-14$ y & $1.01(0.44-2.36)$ & $1.86(1.12-3.15)$ \\
\hline School holidays in the preceding week & $0.68(0.55-0.85)$ & $0.58(0.51-0.65)$ \\
\hline Temperature, ${ }^{\circ} \mathrm{C}$ & $0.991(0.953-1.031)$ & $0.963(0.940-0.987)$ \\
\hline Relative humidity, \% & $0.981(0.972-0.990)$ & $0.997(0.992-1.002)$ \\
\hline Rainfall, mm & $1.009(1.002-1.016)$ & $0.998(0.993-1.002)$ \\
\hline
\end{tabular}

In the preupsurge period, relative humidity (adjusted IRR $0.981,95 \%$ CI $0.972-0.990$ ) and rainfall (adjusted IRR $=1.009 ; 95 \%$ CI $1.002-1.016)$ were significantly associated with incidence of scarlet fever, whereas temperature was not significantly associated. In contrast, in the postupsurge period, temperature had a significant effect on scarlet fever incidence (adjusted IRR 0.963; 95\% CI $0.940-0.987)$, whereas relative humidity and rainfall had an insignificant effect.

\section{Conclusions}

Scarlet fever cases continued to occur in Hong Kong at elevated incidence rates for 5 consecutive years after a major epidemic in 2011. Scarlet fever incidence is higher among younger children entering schools and during school days. School-based control measures, especially for boys 3-5 years of age, could be particularly important in scarlet fever control. A limitation of our study is that we relied on reported cases to study scarlet fever epidemiology, and subclinical infections might have occurred. Moreover, some uncaptured or unobserved factors not considered in this study might have influenced the trend observed. Further community-based studies, including serologic studies, might further elucidate the epidemiology of this reemerging disease.

\section{Acknowledgment}

We thank the Centre for Health Protection, Department of Health, in Hong Kong for their kind support and assistance in collating the notification data.

This project was supported by the Harvard Center for Communicable Disease Dynamics from the National Institute of General Medical Sciences (grant no. U54 GM088558) and a commissioned grant from the Health and Medical Research Fund from the Government of the Hong Kong Special Administrative Region (grant no. HKS-16-E09). The funding bodies had no role in study design, data collection and analysis, preparation of the manuscript, or the decision to publish.

B.J.C. consults for Crucell NV and has received research funding from MedImmune Inc. and Sanofi Pasteur.

Dr. Lee is a research assistant professor in the School of Public Health at the University of Hong Kong. His research interests include antimicrobial resistance and infectious disease epidemiology.

\section{References}

1. Rolleston JD. The history of scarlet fever. BMJ. 1928;2:926-9. http://dx.doi.org/10.1136/bmj.2.3542.926

2. Gale AH. A century of changes in the mortality and incidence of the principal infections of childhood. Arch Dis Child. 1945; 20:2-21. http://dx.doi.org/10.1136/adc.20.101.2

3. Katz AR, Morens DM. Severe streptococcal infections in historical perspective. Clin Infect Dis. 1992;14:298-307. http://dx.doi.org/10.1093/clinids/14.1.298

4. Quinn RW. Comprehensive review of morbidity and mortality trends for rheumatic fever, streptococcal disease, and scarlet fever: the decline of rheumatic fever. Rev Infect Dis. 1989;11:928-53. http://dx.doi.org/10.1093/clinids/11.6.928

5. Guy R, Williams C, Irvine N, Reynolds A, Coelho J, Saliba V, et al. Increase in scarlet fever notifications in the United Kingdom, 2013/2014. Euro Surveill. 2014;19:20749. http://dx.doi.org/10.2807/1560-7917.ES2014.19.12.20749

6. Mahara G, Chhetri JK, Guo X. Increasing prevalence of scarlet fever in China. BMJ. 2016;353:i2689. http://dx.doi.org/10.1136/ bmj.i2689

7. Lau EH, Nishiura H, Cowling BJ, Ip DK, Wu JT. Scarlet fever outbreak, Hong Kong, 2011. Emerg Infect Dis. 2012;18:1700-2. http://dx.doi.org/10.3201/eid1810.120062 
8. Luk EY, Lo JY, Li AZ, Lau MC, Cheung TK, Wong AY, et al. Scarlet fever epidemic, Hong Kong, 2011. Emerg Infect Dis. 2012;18:1658-61. http://dx.doi.org/10.3201/eid1810.111900

9. Davies MR, Holden MT, Coupland P, Chen JH, Venturini C, Barnett TC, et al. Emergence of scarlet fever Streptococcus pyogenes emm 12 clones in Hong Kong is associated with toxin acquisition and multidrug resistance. Nat Genet. 2015;47:84-7. http://dx.doi.org/10.1038/ng.3147

10. Public Health England. Update on rising scarlet fever across England [cited 2016 Aug 23]. https://www.gov.uk/government/ news/update-on-rising-scarlet-fever-across-england

11. Centre for Health Protection, Government of the Hong Kong Special Administrative Region. Number of notifications for notifiable infectious diseases, 2011 [cited 2016 Aug 3]. http://www.chp.gov.hk/en/notifiable1/10/26/43.html

12. Stolwijk AM, Straatman H, Zielhuis GA. Studying seasonality by using sine and cosine functions in regression analysis. J Epidemiol Community Health. 1999;53:235-8. http://dx.doi.org/10.1136/ jech.53.4.235
13. Chen M, Yao W, Wang X, Li Y, Chen M, Wang G, et al. Outbreak of scarlet fever associated with emm 12 type group A streptococcus in 2011 in Shanghai, China. Pediatr Infect Dis J. 2012;31:e158-62. http://dx.doi.org/10.1097/ INF.0b013e31825874f3

14. Wang J, Zhang JQ, Pan HF, Zhu Y, He Q. Epidemiological investigation of scarlet fever in Hefei City, China, from 2004 to 2008. Trop Doct. 2010;40:225-6. http://dx.doi.org/10.1258/ td.2010.090207

15. Mhaske MS, Khismatrao DS, Kevin F, Pandve HT, Kundap RP. Morbidity pattern and personal hygiene in children among private primary school in urban area: are the trends changing? J Family Med Prim Care. 2013;2:266-9. http://dx.doi.org/10.4103/ 2249-4863.120753

Address for correspondence: Benjamin J. Cowling, School of Public Health, Li Ka Shing Faculty of Medicine, The University of Hong Kong,

7 Sassoon Rd, Pokfulam, Hong Kong; email: bcowling@hku.hk

\section{June 2015: Bacterial/Fungal Infections}

- Sequence Type 4821 Clonal Complex Serogroup B Neisseria meningitidis in China, 1978-2013

- Estimated Deaths and Illnesses Averted During Fungal Meningitis Outbreak Associated with Contaminated Steroid Injections, United States, 2012-2013

- Global Burden of Invasive Nontyphoidal Salmonella Disease, 2010
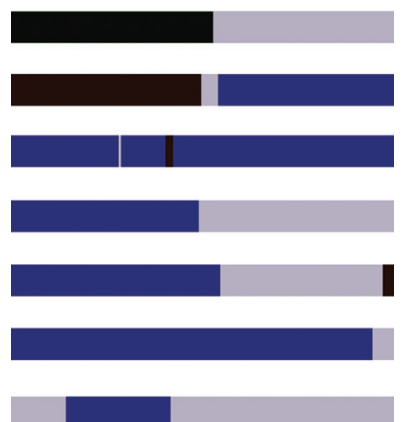

- Dose-Response Relationship between Antimicrobial Drugs and Livestockassociated MRSA in Pig Farming

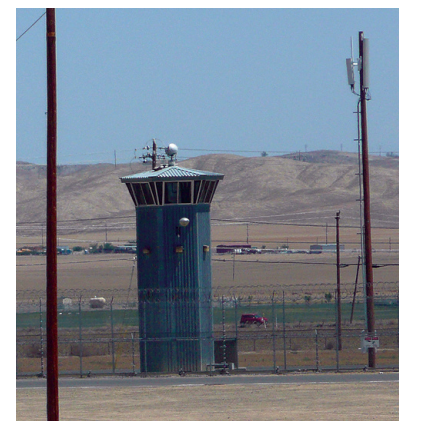

- Cost-effectiveness of Chlamydia Vaccination Programs for Young Women

- Hospitalization Frequency and Charges for Neurocysticercosis, United States, 2003-2012

- Additional Drug Resistance of Multidrug-Resistant Tuberculosis in Patients in 9 Countries

- Oral Cholera Vaccination Coverage, Barriers to Vaccination, and Adverse Events following Vaccination, Haiti, 2013

- Mycobacterium bovis in Panama, 2013
- Endemic Melioidosis in Residents of Desert Region after Atypically Intense Rainfall in Central Australia, 2011

- Invasion Dynamics of White-Nose Syndrome Fungus, Midwestern United States, 2012-2014

- Coccidioides Exposure and Coccidioidomycosis among Prison Employees, California, United States

- Prospective Multicenter International

Surveillance of Azole Resistance in Aspergillus fumigatus

- Oligoarthritis Caused by Borrelia bavariensis, Austria, 2014

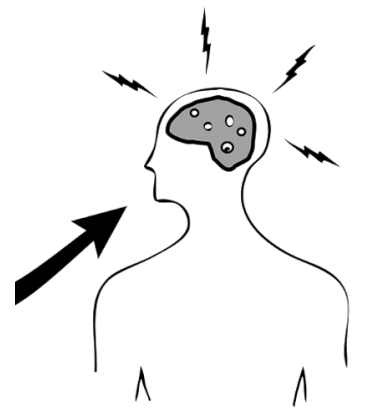

- European Rabbits as Reservoir for Coxiella burnetii

- Drug ResistanceAssociated Mutations in Mycoplasma genitalium in Female Sex Workers, Japan

- Lack of Protection Against Ebola Virus from Chloroquine in Mice and Hamsters

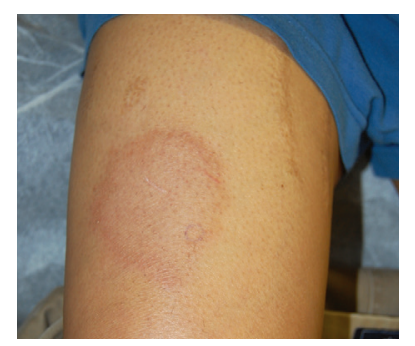

- Wohlfahrtiimonas chitiniclastica Bacteremia Associated with Myiasis, United Kingdom

- Response to Dectection of New Delhi Metallo- $\beta$ Lactamase-Producing Bacteria, Brazil

- Histoplasmosis in Idaho and Montana, USA, 2012-2013 